\title{
Effects of Circulating HMGB-1 and Histones on Cardiomyocytes-Hemadsorption of These DAMPs as Therapeutic Strategy after Multiple Trauma
}

\author{
Birte Weber ${ }^{1}$, Ina Lackner ${ }^{1}$, Meike Baur ${ }^{1}$, Giorgio Fois ${ }^{2}$ (D), Florian Gebhard ${ }^{1}$, Ingo Marzi ${ }^{3}$, \\ Hubert Schrezenmeier ${ }^{4}$, Borna Relja ${ }^{3,5}$ and Miriam Kalbitz ${ }^{1, *}$ \\ 1 Department of Traumatology, Hand-, Plastic- and Reconstructive Surgery, Center of Surgery, University of \\ Ulm, 89081 Ulm, Germany; birte.weber@uni-ulm.de (B.W.); ina.lackner@uni-ulm.de (I.L.); \\ meike.baur@uni-ulm.de (M.B.); florian.gebhard@uniklinik-ulm.de (F.G.) \\ 2 Institute of General Physiology, University of Ulm, 89081 Ulm, Germany; giorgio.fois@uni-ulm.de \\ 3 Department of Trauma, Hand and Reconstructive Surgery, Goethe University of Frankfurt, \\ 60590 Frankfurt, Germany; marzi@trauma.uni-frankfurt.de (I.M.); info@bornarelja.com (B.R.) \\ 4 Institute of Transfusion Medicine, University of Ulm and Institute of Clinical Transfusion Medicine and \\ Immunogenetics Ulm, German Red Cross Blood Transfusion Service Baden-Württemberg-Hessen and \\ University Hospital Ulm, 89081 Ulm, Germany; h.schrezenmeier@blutspende.de \\ 5 Department of Radiology and Nuclear Medicine, Experimental Radiology, Otto-von-Guericke University, \\ 39120 Magdeburg, Germany \\ * Correspondence: miriam.kalbitz@uniklinik-ulm.de
}

Received: 29 March 2020; Accepted: 5 May 2020; Published: 11 May 2020

\begin{abstract}
Background and purpose: The aim of the study was to determine the effects of post-traumatically released High Mobility Group Box-1 protein (HMGB1) and extracellular histones on cardiomyocytes (CM). We also evaluated a therapeutic option to capture circulating histones after trauma, using a hemadsorption filter to treat $\mathrm{CM}$ dysfunction. Experimental Approach: We evaluated cell viability, calcium handling and mitochondrial respiration of human cardiomyocytes in the presence of HMGB-1 and extracellular histones. In a translational approach, a hemadsorption filter was applied to either directly eliminate extracellular histones or to remove them from blood samples obtained from multiple injured patients. Key results: Incubation of human CM with HMGB-1 or histones is associated with changes in calcium handling, a reduction of cell viability and a substantial reduction of the mitochondrial respiratory capacity. Filtrating plasma from injured patients with a hemadsorption filter reduces histone concentration ex vivo and in vitro, depending on dosage. Conclusion and implications: Danger associated molecular patterns such as HMGB-1 and extracellular histones impair human $\mathrm{CM}$ in vitro. A hemadsorption filter could be a therapeutic option to reduce high concentrations of histones.
\end{abstract}

Keywords: hemadsorption; early myocardial damage (EMD), DAMPs; post-traumatic; calcium handling; mitochondrial dysfunction

\section{Introduction}

Early myocardial damage (EMD) after trauma is complex and multifactorial. Patients with elevated troponin levels in the emergency rooms have a higher injury severity score (ISS) and require often catecholamines [1,2].

Post-traumatic cardiac injury can be caused by mechanical forces on the heart, particularly in the case of blunt chest trauma [3-5] or by inflammation, which mediates secondary cardiac damage. Severe trauma often leads to a systemic inflammatory response, accompanied by the release of danger 
associated molecular patterns (DAMPs), such as the high mobility group box-1 protein (HMGB-1) and extracellular histones. In humans, the release of HMGB-1 after trauma has been associated with injury severity, the activation of the complement system and increased mortality rates [6].

Extracellular histones have been linked to trauma-induced lung injury $[7,8]$ and to cardiomyopathy during sepsis in mice [9]. In traumatized patients, enhanced levels of circulating histones were correlated with the Sequential Organ Failure Assessment score, endothelial damage and the activation of the coagulation system [8]. In experimental blunt chest trauma in rats and in experimental multiple trauma in pigs and mice, we observed a systemic release of extracellular histones [3-5].

HMGB-1 and extracellular histones act via Toll-like receptors (TLRs), which trigger the proinflammatory cytokine signalling, which is known to be cardio-depressive: Histones have been shown to act via TLR 2 and 4 on cardiomyocytes [9]. Furthermore, the role of the TLR9 interaction with histones has been described in liver injury [10]. TLR2 and 4 are activated on neutrophils by HMGB-1 [11]. In mice, the interaction between TLR 4 and HMGB-1 has been described in the development of liver injury [12]. Extracellular histones or HMGB-1 interaction with TLR4 increased the release of inflammatory cytokines such as tumor necrosis factor (TNF), interleukin (IL-)1ß and IL-6, which were shown to be cardio-depressive [13-16]. Additionally, histones were linked to the release of HMGB-1 via cell damage in liver, lung and kidney injuries in mice [13]. HMGB-1 is known to provoke cardiomyocyte dysfunction in cardiac hypertrophy, heart failure [17] and myocardial ischemia [18]. Extracellular histones are associated with increased intracellular reactive oxygen species, intracellular calcium in rodent cardiomyocytes and reduced mitochondrial membrane potential and ATP concentration [9].

We propose that HMGB-1 and extracellular histones can set off the development of post-traumatic cardiac dysfunction We also investigated whether hemadsorption may provide a therapeutic option to reduce the negative effects of extracellular histones. Previously, it was shown that hemadsorption improved the outcomes of patients with endotoxemia [19,20], necrotizing fasciitis and septic shock [21]. While the resorption of HMGB- 1 by hemadsorption filter systems has been described before, we assessed the resorption capacity in regard to extracellular histones.

\section{Material and Methods}

\subsection{In Vitro Incubation of Human Cardiomyocytes (CMs) with HMGB-1 and Histones}

Human iPSC-derived cardiomyocytes (iPSC-CMs) were purchased from Cellular Dynamics, USA. The iPSC-CMs \#11713 from Cellular Dynamics were donated from a healthy female donor. The age group at collection was 35-39 years and iPSC-CMs were obtained by episomal reprogramming of PBMC. The cells were cultured for 10 days at $37^{\circ} \mathrm{C}$ and $7 \% \mathrm{CO}_{2}$ in iCell maintenance medium (Cellular Dynamics, Madison, WI, USA). After 10 days cells were incubated with either $100 \mathrm{ng} / \mathrm{mL}$ recombinant human HMGB-1 (R\&D Systems) or with a mixture of $20 \mu \mathrm{g} / \mathrm{mL}$ extracellular histones (Sigma, St Louis, Missouri, USA) for $6 \mathrm{~h}$ at $37^{\circ} \mathrm{C}$ and $7 \% \mathrm{CO}_{2}$. To assess caspase-3/7 activity in treated cardiomyocytes the Caspase-Glo ${ }^{\circledR}$ 3/7 Assay (Promega, Madison, WI, USA) was used. Furthermore, cell viability was measured in the presence of histones or recombinant human HMGB-1 by using the Cell Titer-Glo ${ }^{\circledR}$ Luminescent Cell Viability Assay (Promega, Madison, WI, USA). Additionally, the appearance of HMGB-1 in the supernatant of cardiomyocytes cultured in the presence of histones were detected by using a HMGB-1-ELISA (1BL international, Hamburg, Germany). For all experiments $n=6$.

\subsection{In Vitro Incubation of HL-1 Cells with HMGB-1}

For in vitro experiments, the murine cardiac muscle cell line (HL-1 cells) (Sigma Aldrich, St. Louis, MO, USA) was used. Murine HL-1 cells were cultured in HL-1 expansion medium at $37^{\circ} \mathrm{C}$ in an atmosphere of $5 \% \mathrm{CO}_{2}$. Following this, HL-1 cells were incubated with HMGB-1 (R\&D Systems) for $6 \mathrm{~h}$. Cell viability was detected by using a Cell Titer-GloßLuminescent Cell Viability Assay (Promega, Madison, WI, USA) in the presence of different concentrations of HMGB-1 $(1 \mu \mathrm{g} / \mathrm{mL}, 100 \mathrm{ng} / \mathrm{mL}$, 
$10 \mathrm{ng} / \mathrm{mL}$ ). Moreover, we analysed the metabolic activity of the cells by MTT assay (Invitrogen, Waltham, MA, USA) in the presence of HMGB-1 dose-dependently (after $24 \mathrm{~h}$ of incubation). For all experiments $n=6$.

\subsection{Calcium Measurements}

For calcium measurements, human $\mathrm{CM}$ were incubated with $20 \mu \mathrm{g} / \mathrm{mL}$ histones or with $100 \mathrm{ng} / \mathrm{mL}$ HMGB-1 for $60 \mathrm{~min}$ before the start of the experiments as well as for the duration of the experiment. To measure changes in intracellular $\mathrm{Ca}^{2+}$ concentration, cells were loaded with $5 \mu \mathrm{M}$ Fura-2 (ThermoScientific, Waltham, MA, USA) for $30 \mathrm{~min}$ (in the presence of pharmacological compounds if needed). Fluorescence imaging was performed on a cell observer inverse microscope (Zeiss, Jena, Germany). Cells were illuminated for $90 \mathrm{~ms}$ at a rate of $2 \mathrm{~Hz}$ at each excitation wavelength (340 and $380 \mathrm{~nm}$ ). Images were acquired using MetaFluor (Molecular Devices, Ismaning, Germany). Fura-2 ratios were calculated with ImageJ and the data obtained were analysed with the Matlab script PeakCaller [22]. The images were loaded in ImageJ and after background subtraction Fura-2340/380 ratios were calculated. The Fura-2 ratio traces representing changes in cytoplasmic $\mathrm{Ca}^{2+}$ concentration were analysed with the Matlab script PeakCaller [22] that allows to obtain the values of rise and decay time and height of calcium transients. For all experiments $n=6$.

\subsection{Mitochondrial Respiration}

Mitochondrial respiration was analysed by using the Seahorse XFe96 Analyzer (Agilent Technologies, Santa Clara, CA, USA). For this experiment, human cardiomyocytes (iPS) were seeded in special Seahorse XFe96 cell culture plates (Agilent Technologies, Santa Clara, CA, USA) and were cultured for 10 days in iCell maintenance medium (Cellular Dynamics, Madison, WI, USA) at $37^{\circ} \mathrm{C}$ and $7 \% \mathrm{CO} 2$. After the cultivation, cells were treated either with $20 \mu \mathrm{g} / \mathrm{mL}$ extracellular histones or with $100 \mathrm{ng} / \mathrm{mL}$ HMGB1 in iCell maintenance medium (Cellular Dynamics, Madison, WI, USA) for $5 \mathrm{~h}$ at $37^{\circ} \mathrm{C}$ and $7 \% \mathrm{CO} 2$ and for an additional hour with either $20 \mu \mathrm{g} / \mathrm{mL}$ extracellular histones or with $100 \mathrm{ng} / \mathrm{mL}$ HMGB1 in Agilent Seahorse XF DMEM medium pH 7.4 (Agilent Technologies, Santa Clara, CA, USA), supplemented with $1 \mathrm{mM}$ sodium pyruvate (Sigma Aldrich, St. Louis, MO, USA), 2 mM L-Glutamine (ThermoFisher, Waltham, MA, USA) and $50 \mathrm{mM}$ glucose (Sigma Aldrich, St. Louis, MO, USA) at $37{ }^{\circ} \mathrm{C}$ and $7 \% \mathrm{CO}$. After exposure of the cells to extracellular histones or HMGB1, the mitochondrial respiration was measured. Therefore, the Seahorse XF Cell Mito Stress Test Kit (Agilent Technologies, Santa Clara, CA, USA) was used. With the Seahorse XF Cell Mito Stress Test mitochondrial function of cells can be assessed and multiple parameters are obtained in one assay, including basal respiration, maximal respiration and spare respiratory capacity. During the entire experimental procedure, the oxygen consumption rate $(\mathrm{OCR})$ in $\mathrm{pmol} / \mathrm{min}$ is measured continuously by the Seahorse XFe96 Analyzer (Agilent Technologies, Santa Clara, CA, USA). The mitochondrial respiration was assessed as follows: during the experimental process, $2 \mu \mathrm{M}$ oligomycin, $1 \mu \mathrm{M}$ carbonyl cyanide 4-(trifluoromethoxy) phenylhydrazone (FCCP) and $0.5 \mu \mathrm{M}$ antimycin A and rotenone were added to the cells by programmed injection in defined intervals and after each addition the OCR of the cells were measured. After the experiments, the different parameters for basal respiration, maximal respiration and spare respiratory capacity were calculated by using the Seahorse Wave 2.4 software (Agilent Technologies, Santa Clara, CA, USA). Following this, the obtained parameters of mitochondrial respiration were further normalized on the total amount of mitochondria of the cells. Therefore, the cells were fixed with $4 \%$ formalin at $4{ }^{\circ} \mathrm{C}$ overnight after the experiment. Then, the cells were stained with $0.2 \%$ Janus-Green solution, which specifically stains the mitochondria of cells. Afterwards, cells were washed and resolved with $0.5 \mathrm{M}$ hydrochloric acid. Optical density (OD) was measured at $630 \mathrm{~nm}$, correlating with the amount of cellular mitochondria. Then, the oxygen consumption rate (OCR) values of the mitochondrial parameters were normalized to the OD $630 \mathrm{~nm}$ values, respectively. Results were evaluated using Seahorse Wave 2.4 software (Agilent Technologies, Santa Clara, CA, USA). For all experiments $n=6$. 


\subsection{Plasma Samples of Polytrauma Patients}

Human plasma samples from 20 multiple injured patients with a history of acute blunt or penetrating trauma and an ISS $\geq 16$ were collected after hospital admission to the University Hospital of the Goethe-University Frankfurt. The plasma collection was approved by the institutional ethics committee (312/10), in accordance with the Declaration of Helsinki. All enrolled patients signed the written informed consent form themselves or written informed consent was obtained from the nominated legally authorized representative on the behalf of participants in accordance with ethical standards. Exclusion criteria were younger than 18 or older than 80 years of age, severe burn injury, acute myocardial stroke, cancer or chemotherapy, immunosuppressive drug therapy, HIV, infectious hepatitis, acute cytomegalovirus (CMV) infection and/or thromboembolic events.

Blood samples were withdrawn in ethylenediaminetetraacetic acid (EDTA) tubes (Sarstedt, Nürmbrecht, Germany) directly after admission. The samples were kept on ice until centrifugation at $2100 \times g$ for $15 \mathrm{~min}$. Then the supernatant was collected and stored at $-80^{\circ} \mathrm{C}$ until assay.

\subsection{Hemadsorption in Plasma of Multiple Injured Patients}

We developed small hemadsorption-columns for a volume of $150 \mu \mathrm{L}$ plasma by using a Cytosorb ${ }^{\circledR}$ 300-column (CytoSorbents Inc., Monmouth Junction, NJ, USA). $300 \mu \mathrm{L}$ of the content of the column was aliquoted in Ultrafiltration Spin-Columns ( 0.45 cutoff; Merck Milipore, Billerica, MA, USA) and was centrifuged before incubation with plasma of multiple trauma patients. After $6 \mathrm{~h}$ of incubation an additional centrifugation followed. The samples were then stored at $-80{ }^{\circ} \mathrm{C}$. Furthermore, we investigated a dose-depending hemadsorption-curve of histones (mixture of histones). Therefore, histones of calf thymus were diluted in Aqua dest. with the concentrations 700, 500, 300, 200, 100, 50 and $25 \mu \mathrm{g} / \mathrm{mL}$. They were incubated for $6 \mathrm{~h}$ on a plate shaker and were centrifuged before measuring the histone concentrations.

\subsection{Statistical Procedures}

All values are expressed as mean \pm SEM. Data were analysed by one-way ANOVA followed by Dunnett's or Tukey's multiple comparison test. Students $t$-test was used in the case of comparison of two groups. $p \leq 0.05$ is considered statistically significant. GraphPad Prism 7.0 software was used for statistical analysis (GraphPad Software, Incorporated, San Diego, CA, USA).

\section{Results}

\subsection{Decreased Apoptosis in Human Cardiomyocytes and Alterations of Calcium Handling in Presence of HMGB-1 and Histones}

In the presence of histones, cell viability of cardiomyocytes was significantly reduced (Figure 1A), whereas the detection of pro-apoptotic caspase was neither changed in the histone nor in the HMGB-1 treated CM (Figure 1B). We also investigated changes in calcium handling of $C M$ in the presence of histones or HMGB1. The mean height calcium signal was reduced in the presence of HMGB-1 (Figure 1C), while the mean rise time of the calcium signal was neither changed in the presence of histones nor after incubation with HMGB-1 (Figure 1D). In Figure 1E, we demonstrate the increase of the mean decay time of the calcium signal in presence of histones. Furthermore, the frequency of the calcium signal in CM was significant reduced in the presence of histones, as well as after incubation with HMGB-1, which was associated with bradycardia of the CMs in vitro (Figure 1F). 

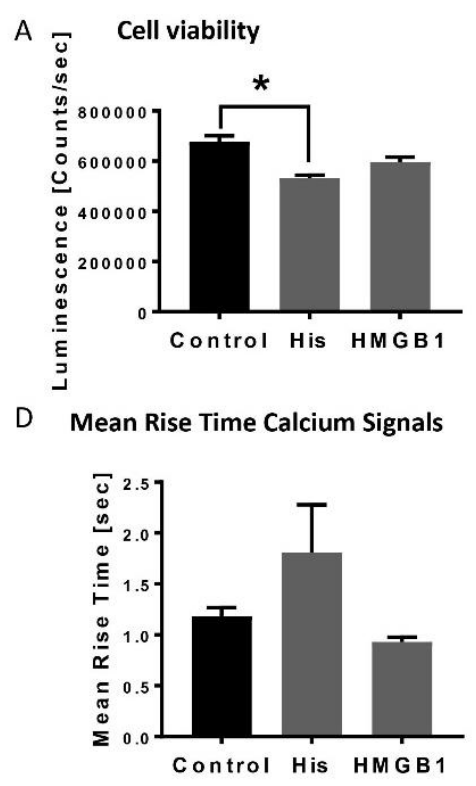

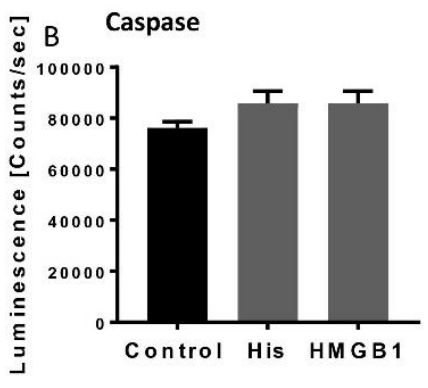

E Mean Decay Time Calcium Signals

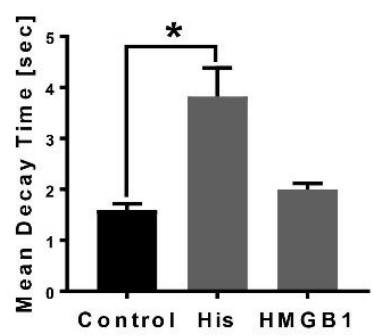

C Mean Height Calcium Signals

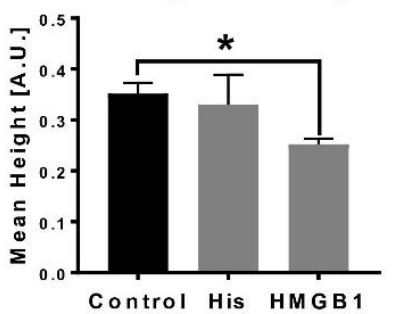

F Frequency Calcium Signaling

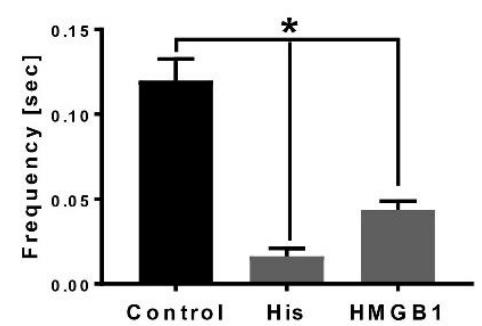

Figure 1. Decrease in cardiomyocytes viability, apoptosis and alterations of calcium handling in the presence of HMGB-1 and histones: Cell viability of human cardiomyocytes (Luminescence in counts/sec) in the presence of $20 \mu \mathrm{g} / \mathrm{mL}$ histones (His) and $100 \mathrm{ng} / \mathrm{mL} \mathrm{HMGB}-1\left(37^{\circ} \mathrm{C}, 6 \mathrm{~h}\right)$ compared to the control (PBS) (A). Caspase-3/7 activity (counts/sec) in human CMs in the presence of histones and HMGB-1 (B). Mean Height calcium signals (A.U) in the presence of histones and HMGB-1 compared to the control (C). Mean rise time (sec) (D) and mean decay time (sec) (E) of calcium peaks of human CMs in the presence of histones and HMGB-1. Frequency of calcium signals (sec) in human cardiomyocytes treated $20 \mu \mathrm{g} / \mathrm{mL}$ histones and $100 \mathrm{ng} / \mathrm{mL}$ HMGB-1 (F). Results are presented as mean $\pm \mathrm{SEM}$, for all experiments $n=6$. Indicated results were significant $* p<0.05$.

\subsection{Decrease in HL-1 Cell Viability and Metabolic Activity in Presence of Different HMGB-1 Concentrations}

Cell viability of HL-1 cells were significantly reduced in the presence of $1 \mu \mathrm{g} / \mathrm{mL}, 100 \mathrm{ng} / \mathrm{mL}$ as well as $10 \mathrm{ng} / \mathrm{mL}$ HMGB-1 (Figure 2A). By conducting the MTT assay, we detected a reduction of metabolic activity in the HL-cells in the presence of all tested HMGB-1 concentrations (Figure 2B).

A

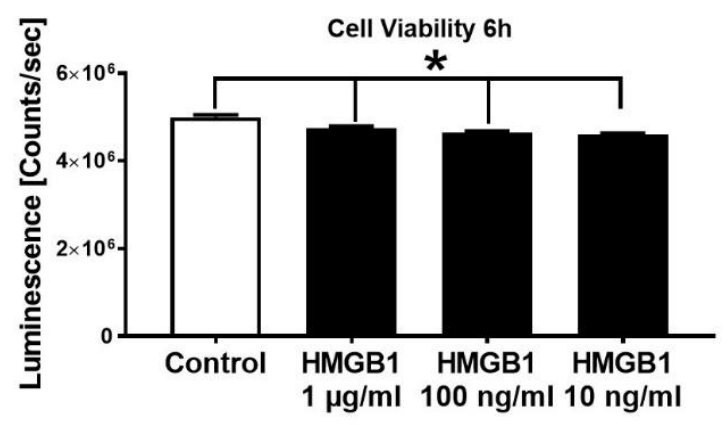

B

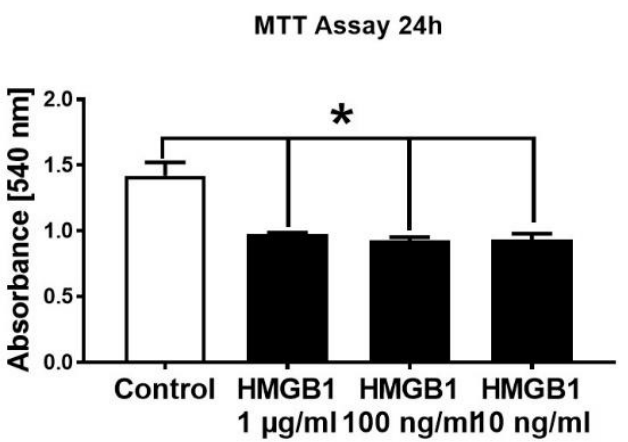

Figure 2. Decrease in HL-1 cell viability and metabolic activity in the presence of different HMGB-1 concentrations. HL-1 cell viability in the presence of different HMGB-1 concentrations after $6 \mathrm{~h}$ of incubation compared to control-HL-1 cell viability (A). Metabolic activity measured in HL-1 cells in the presence of different HMGB-1 concentrations incubated for $24 \mathrm{~h}$ compared to controls (B). $n=6$. Results were significant ${ }^{*} p<0.05$. 


\subsection{Metabolic Alterations of Human Cardiomyocytes in Presence of Histones}

Metabolic alterations of human CMs in the presence of a mixture of histones or HMGB-1 were investigated. The basal respiration decreased tendentially in the presence of histones or HMGB1 compared to the control group (Figure 3A,D). Moreover, we observed a decrease of the maximal respiration capacity in the presence of both HMGB-1 and histones (Figure 3B,E). In addition, the spare respiratory capacity decreased significantly in the presence of histones or HMGB-1 (Figure 3C,F).
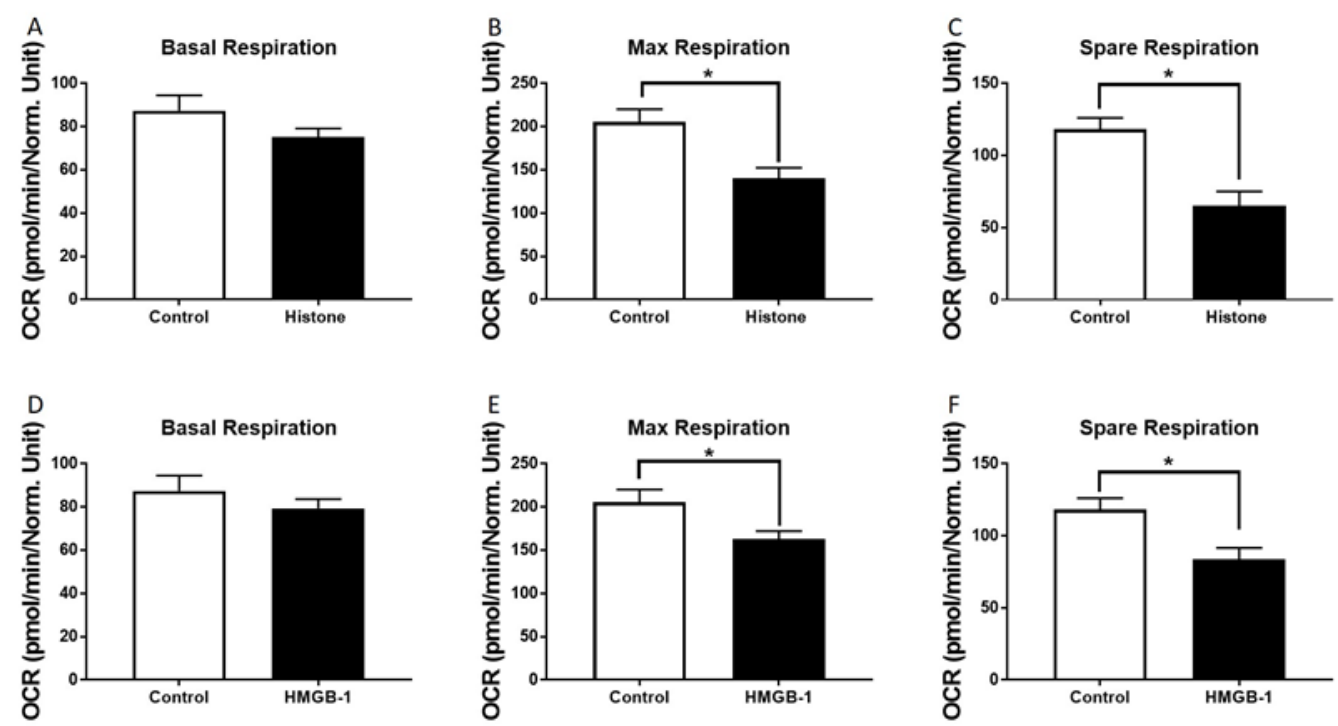

Figure 3. Metabolic alterations of human cardiomyocytes $(\mathrm{CM})$ in the presence of histones: Basal respiration (OCR in pmol/m in/Norm. unit) of human CMs in the presence of $20 \mu \mathrm{g} / \mathrm{mL}$ histones $\left(37^{\circ} \mathrm{C}, 6 \mathrm{~h}\right)(\mathbf{A})$. Maximal respiratory capacity (OCR in $\mathrm{pmol} / \mathrm{m}$ in/Norm. unit) of human CMs in the presence of $20 \mu \mathrm{g} / \mathrm{mL}$ histones compared to the control (PBS) (B). Spare respiration (OCR in $\mathrm{pmol} / \mathrm{m}$ in/Norm. unit) of human CMs in the presence of $20 \mu \mathrm{g} / \mathrm{mL}$ histones $\left(37^{\circ} \mathrm{C}, 6 \mathrm{~h}\right)(\mathbf{C})$. Basal respiration (D), max respiratory capacity $(\mathbf{E})$ and spare respiration $(\mathbf{F})$ of human $\mathrm{CM}$ in the presence of $100 \mathrm{ng} / \mathrm{mL}$ HMGB-1. Results are presented as mean SEM, for all experiments $n=6$. Results are significant ${ }^{*} p<0.05$, statistical analysis with $t$-test.

\subsection{Hemadsorption-A Therapeutic Option to Eliminate Systemic Extracellular Histones}

To evaluate the therapeutic potential of hemadsorption we analysed the absorption capability and capacity for extracellular histones by CytoSorb®300. After incubation of different histone concentrations, the levels decreased between 92\% and 99\% within $6 \mathrm{~h}$ (Figure 4A). Moreover, extracellular histone concentration in blood samples of multiple injured patients collected at admission to the hospital significantly dropped after absorption by the hemadsorption filter (Figure 4B). 
A

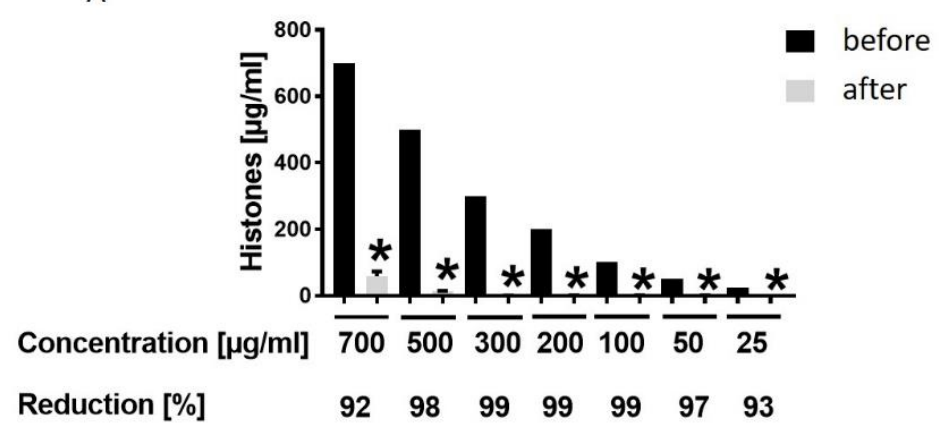

B

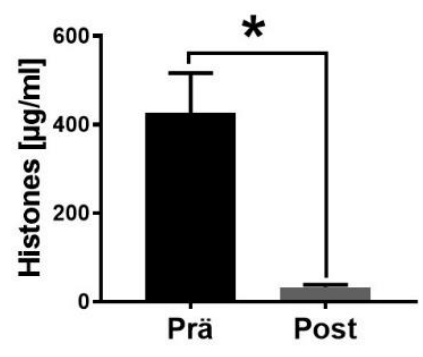

Figure 4. Hemadsorption-a therapeutic option to eliminate systemic extracellular histones. (A). Hemadsoption of different concentrations of histones (700, 500, 300, 200, 100, 50, $25 \mu \mathrm{g} / \mathrm{mL}$ ) presented as percentage of reduction (\%) after 6 hrs incubation time; for all concentrations $n=6$. (B). Histone levels in blood plasma of 22 multiple injured humans $(\mu \mathrm{g} / \mathrm{mL})$ in the Emergency room (pre) and after hemadsorption for $6 \mathrm{~h}$ (post). Results were presented as SEM, ${ }^{*} p<0.05$.

\section{Discussion}

In this report, we demonstrated the detrimental effects of HMGB- 1 and histones on cardiomyocytes. Recent studies revealed an increase of circulatory histones after experimental blunt chest trauma in rats [4], after multiple trauma in pigs [3] and of circulating HMGB-1 in pigs after multiple trauma [23]; observed together with depressed cardiac function [3]. The presented data underpins that both HMGB-1 and extracellular histones impair myocardial functions, leading to consequences such as a deceleration of frequency of $\mathrm{CMs}$ and an impaired mitochondrial respiration in vitro.

The role of HMGB1 on cardiac function and the potential detrimental effects are controversial so far. On the one hand, HMGB-1 is systemically elevated in models of myocarditis and ischemic myocardial infarction in mice [24]. In addition, the application of anti-HMGB-1 antibody in hemorrhagic shock in mice was associated with decreased systemic release of cardiac enzymes, reduced local ATP depletion and systemic levels of inflammatory mediators like TNF and IL-1ß [25]. Extracellular HMGB-1 binds directly to TLR 4 as well as to the receptor for advanced glycation end products (RAGE), which was linked to the production and release of inflammatory cytokines [14,15] such as TNF, IL-1ß and IL-6 [16], which were shown to be cardio-depressive [26]. An increase of systemic IL-6 concentration has been linked to cardiac dysfunction, demonstrated as a reduction of stroke volume, cardiac output and the performance of the left ventricle $[27,28]$. In rat CMs the presence of TNF and IL- $1 ß$ led to dysfunction of the calcium balance: it prolongs the calcium transient duration and therefore the action potential, as well as leads to asynchronous calcium release during electrical stimulation. Further, these cytokines increased the vulnerability of the sarcoplasmic reticulum for spontaneous calcium leakage. TNF and IL-1ß depressed calcium transient, the contractility and therefore have been linked to arrhythmogenicity in ventricular rat CM [29]. The presence of IL-1B could be associated with prolonged action potential duration, the reduction of the transient potassium current of $35 \%$, therefore a reduced repolarization in $\mathrm{CM}$ and again the increase of diastolic sarcoplasmic calcium leakage. Together, these changes led to high potential of cardiac arrythmias [30]. Furthermore, RAGE-knock out mice showed lower myocardial inflammation and fibrosis compared to wild-type mice in a model of inflammatory heart disease [31]. Besides, these effects HMGB-1 was shown to influence the post-traumatic development of microvascular thrombosis and endothelial cell activation via inhibition of the anticoagulant protein $C$ pathway mediated by the thrombin-thrombomodulin complex, and further stimulated tissue factor expression on monocytes [32]. High plasma levels of HMGB1 are associated with increased complement activity as indicated by elevated soluble C $5 \mathrm{~b}-9$ plasma levels that are generated during the late phase of complement activation [6]. The connection between complement activation and cardiac depression is well described after trauma [33] and sepsis [34,35]. 
On the other hand, Limana, et al. (2005) [36] injected low-dose HMGB-1 in the left ventricles of infarcted mice hearts and observed a partial reconstitution of the defect by a myocardial population after one week compared to the beginning of scar formation in non-HMGB-1 treated animals. The intervention with HMGB-1 resulted in the formation of new myocytes within the infarcted portion of the wall via the proliferation and differentiation of endogenous cardiac c-kit+ progenitor cells [36]. In addition, ejection fraction measured by echocardiography improved in the locally HMGB-1 treated animals after myocardial infarction [36]. The application of HMGB-1 after myocardial infarction also decreased levels of IL-1, IL-6, IL-10 and vascular endothelial growth factor (VEGF) [37]. Transgenic mice with an overexpression of cardiac-specific HMGB-1 were protected against the consequences of myocardial infarction [38], whereas animals with HMGB1 null mutation are nonviable [39].

However, our in vitro data demonstrates a deceleration of the natural frequency of human CMs, as well as changes in the calcium handling in the presence of HMGB-1 and a reduction in mitochondrial respiration. This clearly indicates the negative effects of HMGB-1.

Therefore, therapeutic elimination of high systemic concentrations of HMGB-1 might be an option to reduce cardiac dysfunction after trauma. microRNA-26a inhibited the HMGB-1 expression in an ischemic/reperfusion model, which is correlated with less infiltration of inflammatory cells and a decreased cytokine release [40]. Moreover, an overexpression of microRNA-142-3p targeting HMGB-1 gene in mouse cardiomyocytes presented a significantly lower apoptotic rate as controls after [41]. However, the context of trauma cardiac damage is complex and multifactorial. Therefore, a multipotent therapeutic option could be a hemadsorption filter, which was described to be useful for the elimination of not only HMGB-1 [42] but also other inflammatory molecules such as cytokines, midkine or active complement components [43,44]. The presented report demonstrates the initial usefulness of hemadsorption filters to eliminate extracellular histones. Further studies need to evaluate the therapeutic clinical use after trauma.

Recently circulating histones were discussed as new biomarkers after trauma $[45,46]$. In previous studies we demonstrated that histones bind to the surface of rat CMs [9]. Incubation of human cardiomyocytes with histones increased the levels of cytosolic reactive oxygen species (ROS) [9]. This observation was dose-dependent [9]. Increased intracellular ROS levels were associated with increased cytosolic calcium concentration in CMs by modulating calcium handling proteins [47] and by blocking the sarcoplasmic endoplasmic reticulum-transporting ATPase (SERCA) [48]. The data revealed that calcium signalling in human CMs was disturbed in the presence of histones and HMGB-1. The frequency of calcium signals decreased either in the presence of HMGB-1 or histones. This was in line with findings obtained from Langendorff perfused mouse hearts in the presence of histones, which showed sinus bradycardia as well as the development of ventricular bigeminy in the ECG [9]. Moreover, this report shows that the mean decay time of the single calcium peaks were altered in human CMs in the presence of histones, which was in accordance with earlier findings demonstrating disturbed calcium handling by enhanced build-up of $\left(\mathrm{Ca}^{2+}\right)$ [34]. Apart from that, it is also known that histones interact with the phospholipid-membrane of cells, which leads to higher permeability and a calcium influx in cells [8,49-51]. Rat CM incubated with histones featured increased intracellular calcium, which was demonstrated to be dependent on the expression of TLR2 and 4. In the absence of TLR2 or 4 increases of intracellular calcium in cardiomyocytes in the presence of extracellular histones were ameliorated [9].

Increased intracellular calcium concentration have been linked to the cell toxicity of extracellular histones [8]. Alhamdi et al. (2015) [52] cultured cardiomyocytes with the plasma of patients with sepsis, resulting in a significant reduction of cell viability after incubation with serum containing $>75 \mu \mathrm{g} / \mathrm{mL}$ histones compared to incubation with the sera of healthy controls [52]. In the present study, the cell viability of human cardiomyocytes was decreased in the presence of $20 \mu \mathrm{g} / \mathrm{mL}$ extracellular histones. The caspase $3 / 7$ activity did not change compared to the controls.

As presented in Figure 1, the presence of histone led to changes in mitochondrial respiration, especially the spare respiratory capacity, which was impaired. These findings were in accordance with 
earlier studies demonstrating reduced mitochondrial membrane potential in isolated rat CMs in the presence of extracellular histones [9].

Therapeutically, anti-histone antibodies have been applied experimentally to reduce high systemic histone concentrations [52,53]. Furthermore, the application of anti-histone antibodies improved cardiac dysfunction in mice with cecal ligation and puncture induced sepsis $[9,52]$. Hemadsorption is routinely used in critically ill patients [19-21]. Here, we proved for the first time that this filter system reduced high concentrations of extracellular histones. Therefore, the hemadsorption is a promising therapeutic option in severely injured patients because of its multifactorial character. It has been shown to not only reduce extracellular histones and HMGB1 but also complement factor C5a and cytokines [19-21,42]. Hemadsorption may have to mitigate the consequences of these factors that have all been linked to cardiac damage and cardiac dysfunction. In further clinical studies, the advantages of hemadsorption in multiple injured patients has to be evaluated in regard to its ability to ameliorate EMD.

One major limitation of the present study is the missing testing of CMs function in the presence of a patient's plasma before and after hemadsorption. A potential depression of CMs function could be examined by analysis of the mitochondrial respiration (basal, spare and maximal respiration) as well as of the CMs contraction in the presence of non-filtered and filtered polytrauma plasma. Furthermore, the positive effects of hemadsorption could be investigated by intracellular calcium measurements, including the analysis of the mRNA expression of important calcium-handling proteins (NCX or SERCA). Further experiments could also include structural changes in human CMs in the presence of filtered and non-filtered polytrauma plasma, for example the measurement of connexins, intracellular troponin, alpha-actinin or desmin. Although these experiments seem interesting and would fit well in the context of the manuscript, they are beyond its scope.

The focus of the present report lies in the distinct effects of HMGB-1 and extracellular histones on human CMs functionality. In a previous study, we treated human CMs with a defined polytrauma-cocktail, including miscellaneous inflammatory cytokines, complement activation products and DAMPs (IL-1B, IL-6, IL-8, TNF, C5a, C3a, HMGB1 and extracellular histones), mimicking the inflammatory conditions of multiple trauma in vitro [54]. In this study, we demonstrated that the entirety of these inflammatory molecules acted detrimentally on the CMs, impairing their cellular glucose and fatty acid transport, which might contribute to impaired cardiac function after multiple trauma [55]. However, our main focus lies on the specific effects of the individual components, therefore we treated the cells either with HMGB1 or with extracellular histones in the present study. Moreover, we did not use the plasma before and after hemadsorption, because we cannot exclude that the effects on CMs were mediated via other cytokines or DAMPs. The hemadsorption filter system was shown to reduce unpacifically the concentration of a wide range of inflammatory- and damaging molecules, therefore it is used for treatment of patients with SIRS or sepsis. In order to understand the complex pathomechanism of post-traumatic cardiac dysfunction, the particular influence of the individual DAMPs on CMs should be tested primarily as well as the filtration capacity of the hemadsorption column for these specific molecules. Moreover, in order to further verify the distinct effects of the single components, neutralizing antibodies might be used. However, this was not the goal of the present study and should be investigated in detail in future studies. A correct assignment between damaging mediators, their effects on CMs and the benefit of a mediator's reduction is only possible due to precise testing of the individual mediators.

\section{Conclusions}

To summarise, this study confirms that nuclear proteins provoke cardiac damage and cardiac dysfunction after trauma. HMGB-1 and extracellular histones are released after multiple trauma. Despite their positive roles in the immune reaction, these mediators are associated with detrimental effects on cardiomyocytes including their viability, calcium handling and mitochondrial function. 
The study also shows that hemadsorption is a useful therapeutic option to reduce DAMPs concentrations and to potentially ameliorate EMD after trauma.

Author Contributions: Regarding contributions of the authors B.W., I.L., M.B., B.R., G.F. performed the experiments including cell culture experiments and ELISAs. B.W. and M.K. primarily wrote the paper. B.R., I.M., F.G., H.S. and M.K. contributed to the experimental design and data analysis and coordinated the study and supervised financial support for the studies. All authors made substantial contributions to the conception and design of the study and participated in drafting the article. All authors gave final approval of the version to be published.

Funding: This work is supported by Deutsche Forschungsgemeinschaft grant CRC1149 "Danger Response, Disturbance Factors and Regenerative Potential after Acute Trauma", project number 251293561.

Acknowledgments: We kindly acknowledge the Department of Children and Adolescent Medicine, Division of Pediatric Endocrinology and Diabetes for the provision of the Agilent Seahorse XFe96 analyzer.

Conflicts of Interest: The authors declare that the research was conducted in the absence of any commercial or financial relationships that could be construed as potential conflicts of interest. The funders had no role in the design of the study; in the collection, analyses, or interpretation of data; in the writing of the manuscript, or in the decision to publish the results.

\section{References}

1. Kalbitz, M.; Pressmar, J.; Stecher, J.; Weber, B.; Weiss, M.; Schwarz, S.; Miltner, E.; Gebhard, F.; Huber-Lang, M. The Role of Troponin in Blunt Cardiac Injury After Multiple Trauma in Humans. World J. Surg. 2017, 41, 162-169. [CrossRef]

2. Martin, M.; Mullenix, P.; Rhee, P.; Belzberg, H.; Demetriades, D.; Salim, A. Troponin increases in the critically injured patient: Mechanical trauma or physiologic stress? J. Trauma 2005, 59, 1086-1091. [CrossRef]

3. Kalbitz, M.; Schwarz, S.; Weber, B.; Bosch, B.; Pressmar, J.; Hoenes, F.M.; Braun, C.K.; Horst, K.; Simon, T.P.; Pfeifer, R.; et al. Cardiac Depression in Pigs after Multiple Trauma-Characterization of Posttraumatic Structural and Functional Alterations. Sci. Rep. 2017, 7, 17861. [CrossRef]

4. Kalbitz, M.; Amann, E.M.; Bosch, B.; Palmer, A.; Schultze, A.; Pressmar, J.; Weber, B.; Wepler, M.; Gebhard, F.; Schrezenmeier, H.; et al. Experimental blunt chest trauma-induced myocardial inflammation and alteration of gap-junction protein connexin 43. PLoS ONE 2017, 12, e0187270. [CrossRef]

5. Braun, C.K.; Kalbitz, M.; Halbgebauer, R.; Eisele, P.; Messerer, D.A.C.; Weckbach, S.; Schultze, A.; Braumuller, S.; Gebhard, F.; Huber-Lang, M.S. Early structural changes of the heart after experimental polytrauma and hemorrhagic shock. PLoS ONE 2017, 12, e0187327. [CrossRef]

6. Cohen, M.J.; Brohi, K.; Calfee, C.S.; Rahn, P.; Chesebro, B.B.; Christiaans, S.C.; Carles, M.; Howard, M.; Pittet, J.-F. Early release of high mobility group box nuclear protein 1 after severe trauma in humans: Role of injury severity and tissue hypoperfusion. Crit. Care 2009, 13, 174. [CrossRef]

7. Ward, P.A.; Grailer, J.J. Acute lung injury and the role of histones. Transl. Respir. Med. 2014, 2, 1. [CrossRef]

8. Abrams, S.T.; Zhang, N.; Manson, J.; Liu, T.; Dart, C.; Baluwa, F.; Wang, S.S.; Brohi, K.; Kipar, A.; Yu, W.; et al. Circulating histones are mediators of trauma-associated lung injury. Am. J. Respir. Crit. Care Med. 2013, 187, 160-169. [CrossRef]

9. Kalbitz, M.; Grailer, J.J.; Fattahi, F.; Jajou, L.; Herron, T.J.; Campbell, K.F.; Zetoune, F.S.; Bosmann, M.; Sarma, J.V.; Huber-Lang, M.; et al. Role of extracellular histones in the cardiomyopathy of sepsis. FASEB J. 2015, 29, 2185-2193. [CrossRef]

10. Huang, H.; Tohme, S.; Al-Khafaji, A.B.; Tai, S.; Loughran, P.; Chen, L.; Wang, S.; Kim, J.; Billiar, T.; Wang, Y.; et al. Damage-associated molecular pattern-activated neutrophil extracellular trap exacerbates sterile inflammatory liver injury. Hepatology 2015, 62, 600-614. [CrossRef]

11. Park, J.S.; Svetkauskaite, D.; He, Q.; Kim, J.-Y.; Strassheim, D.; Ishizaka, A.; Abraham, E. Involvement of toll-like receptors 2 and 4 in cellular activation by high mobility group box 1 protein. J. Biol. Chem. 2004, 279, 7370-7377. [CrossRef]

12. Tsung, A.; Sahai, R.; Tanaka, H.; Nakao, A.; Fink, M.P.; Lotze, M.T.; Yang, H.; Li, J.; Tracey, K.J.; Geller, D.A.; et al. The nuclear factor HMGB1 mediates hepatic injury after murine liver ischemia-reperfusion. J. Exp. Med. 2005, 201, 1135-1143. [CrossRef] 
13. Kawai, C.; Kotani, H.; Miyao, M.; Ishida, T.; Jemail, L.; Abiru, H.; Tamaki, K. Circulating Extracellular Histones Are Clinically Relevant Mediators of Multiple Organ Injury. Am. J. Pathol. 2016, 186, 829-843. [CrossRef]

14. Asavarut, P.; Zhao, H.; Gu, J.; Ma, D. The role of HMGB1 in inflammation-mediated organ injury. Acta Anaesthesiol. Taiwan 2013, 51, 28-33. [CrossRef]

15. Van Beijnum, J.R.; Buurman, W.A.; Griffioen, A.W. Convergence and amplification of toll-like receptor (TLR) and receptor for advanced glycation end products (RAGE) signaling pathways via high mobility group B1 (HMGB1). Angiogenesis 2008, 11, 91-99. [CrossRef]

16. Meng, X.-Y.; Wu, L.; Zhou, Y.-H.; Liu, T.; Han, Q.-F.; Zhang, D.-Y.; Wang, L.-H.; Yao, H.-C. High mobility group box 1 might be a novel therapeutic target in ischemia heart disease. Int. J. Cardiol. 2016, 206, 42-43. [CrossRef]

17. Zhang, L.; Liu, M.; Jiang, H.; Yu, Y.; Yu, P.; Tong, R.; Wu, J.; Zhang, S.; Yao, K.; Zou, Y.; et al. Extracellular high-mobility group box 1 mediates pressure overload-induced cardiac hypertrophy and heart failure. J. Cell. Mol. Med. 2016, 20, 459-470. [CrossRef]

18. Tian, Y.; Charles, E.J.; Yan, Z.; Wu, D.; French, B.A.; Kron, I.L.; Yang, Z. The myocardial infarct-exacerbating effect of cell-free DNA is mediated by the high-mobility group box 1-receptor for advanced glycation end products-Toll-like receptor 9 pathway. J. Thorac. Cardiovasc. Surg. 2018, 157, 2256-2269. [CrossRef]

19. Peng, Z.-Y.; Carter, M.J.; Kellum, J.A. Effects of hemoadsorption on cytokine removal and short-term survival in septic rats. Crit. Care Med. 2008, 36, 1573-1577. [CrossRef]

20. Kellum, J.A.; Song, M.; Venkataraman, R. Hemoadsorption removes tumor necrosis factor, interleukin-6, and interleukin-10, reduces nuclear factor-kappaB DNA binding, and improves short-term survival in lethal endotoxemia. Crit. Care Med. 2004, 32, 801-805. [CrossRef]

21. Hinz, B.; Jauch, O.; Noky, T.; Friesecke, S.; Abel, P.; Kaiser, R. CytoSorb, a novel therapeutic approach for patients with septic shock: A case report. Int. J. Artif. Organs 2015, 38, 461-464. [CrossRef]

22. Artimovich, E.; Jackson, R.K.; Kilander, M.B.C.; Lin, Y.-C.; Nestor, M.W. PeakCaller: An automated graphical interface for the quantification of intracellular calcium obtained by high-content screening. BMC Neurosci. 2017, 18, 72. [CrossRef]

23. Horst, K.; Hildebrand, F.; Pfeifer, R.; Hubenthal, S.; Almahmoud, K.; Sassen, M.; Steinfeldt, T.; Wulf, H.; Ruchholtz, S.; Pape, H.C.; et al. Impact of haemorrhagic shock intensity on the dynamic of alarmins release in porcine poly-trauma animal model. Eur. J. Trauma Emerg. Surg. 2016, 42, 67-75. [CrossRef]

24. Wang, H.; Bloom, O.; Zhang, M.; Vishnubhakat, J.M.; Ombrellino, M.; Che, J.; Frazier, A.; Yang, H.; Ivanova, S.; Borovikova, L.; et al. HMG-1 as a late mediator of endotoxin lethality in mice. Science 1999, 285, 248-251. [CrossRef]

25. Zhou, Y.; Li, Y.; Mu, T. HMGB1 Neutralizing Antibody Attenuates Cardiac Injury and Apoptosis Induced by Hemorrhagic Shock/Resuscitation in Rats. Biol. Pharm. Bull. 2015, 38, 1150-1160. [CrossRef]

26. Kumar, A.; Thota, V.; Dee, L.; Olson, J.; Uretz, E.; Parrillo, J.E. Tumor necrosis factor alpha and interleukin 1 beta are responsible for in vitro myocardial cell depression induced by human septic shock serum. J. Exp. Med. 1996, 183, 949-958. [CrossRef]

27. Yang, S.; Zheng, R.; Hu, S.; Ma, Y.; Choudhry, M.A.; Messina, J.L.; Rue, L.W., III; Bland, K.I.; Chaudry, I.H. Mechanism of cardiac depression after trauma-hemorrhage: Increased cardiomyocyte IL-6 and effect of sex steroids on IL-6 regulation and cardiac function. Am. J. Physiol. Heart Circ. Physiol. 2004, 287, 2183-2191. [CrossRef]

28. Yang, S.; Hu, S.; Hsieh, Y.-C.; Choudhry, M.A.; Rue, L.W., III; Bland, K.I.; Chaudry, I.H. Mechanism of IL-6-mediated cardiac dysfunction following trauma-hemorrhage. J. Mol. Cell. Cardiol. 2006, 40, 570-579. [CrossRef]

29. Duncan, D.J.; Yang, Z.; Hopkins, P.M.; Steele, D.S.; Harrison, S.M. TNF-alpha and IL-1beta increase Ca2+ leak from the sarcoplasmic reticulum and susceptibility to arrhythmia in rat ventricular myocytes. Cell Calcium 2010, 47, 378-386. [CrossRef]

30. Monnerat, G.; Alarcon, M.L.; Vasconcellos, L.R.; Hochman-Mendez, C.; Brasil, G.; Bassani, R.A.; Casis, O.; Malan, D.; Travassos, L.H.; Sepulveda, M.; et al. Macrophage-dependent IL-1beta production induces cardiac arrhythmias in diabetic mice. Nat. Commun. 2016, 7, 13344. [CrossRef] 
31. Bangert, A.; Andrassy, M.; Muller, A.-M.; Bockstahler, M.; Fischer, A.; Volz, C.H.; Leib, C.; Goser, S.; Korkmaz-Icoz, S.; Zittrich, S.; et al. Critical role of RAGE and HMGB1 in inflammatory heart disease. Proc. Natl. Acad. Sci. USA 2016, 113, 155-164. [CrossRef] [PubMed]

32. Ito, T.; Kawahara, K.; Nakamura, T.; Yamada, S.; Abeyama, K.; Hashiguchi, T.; Maruyama, I. High-mobility group box 1 protein promotes development of microvascular thrombosis in rats. J. Thromb. Haemost. 2007, 5, 109-116. [CrossRef] [PubMed]

33. Lackner, I.; Weber, B.; Baur, M.; Fois, G.; Gebhard, F.; Pfeifer, R.; Cinelli, P.; Halvachizadeh, S.; Lipiski, M.; Cesarovic, N.; et al. Complement Activation and Organ Damage After Trauma-Differential Immune Response Based on Surgical Treatment Strategy. Front. Immunol. 2020, 11, 64. [CrossRef]

34. Kalbitz, M.; Fattahi, F.; Herron, T.J.; Grailer, J.J.; Jajou, L.; Lu, H.; Huber-Lang, M.; Zetoune, F.S.; Sarma, J.V.; Day, S.M.; et al. Complement Destabilizes Cardiomyocyte Function In Vivo after Polymicrobial Sepsis and In Vitro. J. Immunol. 2016, 197, 2353-2361. [CrossRef]

35. Fattahi, F.; Frydrych, L.M.; Bian, G.; Kalbitz, M.; Herron, T.J.; Malan, E.A.; Delano, M.J.; Ward, P.A. Role of complement C5a and histones in septic cardiomyopathy. Mol. Immunol. 2018, 102, 32-41. [CrossRef]

36. Limana, F.; Germani, A.; Zacheo, A.; Kajstura, J.; Di Carlo, A.; Borsellino, G.; Leoni, O.; Palumbo, R.; Battistini, L.; Rastaldo, R.; et al. Exogenous high-mobility group box 1 protein induces myocardial regeneration after infarction via enhanced cardiac C-kit+ cell proliferation and differentiation. Circ. Res. 2005, 97, 73-83. [CrossRef]

37. Abarbanell, A.M.; Hartley, J.A.; Herrmann, J.L.; Weil, B.R.; Wang, Y.; Manukyan, M.C.; Poynter, J.A.; Meldrum, D.R. Exogenous high-mobility group box 1 improves myocardial recovery after acute global ischemia/reperfusion injury. Surgery 2011, 149, 329-335. [CrossRef]

38. Kitahara, T.; Takeishi, Y.; Harada, M.; Niizeki, T.; Suzuki, S.; Sasaki, T.; Ishino, M.; Bilim, O.; Nakajima, O.; Kubota, I. High-mobility group box 1 restores cardiac function after myocardial infarction in transgenic mice. Cardiovasc. Res. 2008, 80, 40-46. [CrossRef]

39. Calogero, S.; Grassi, F.; Aguzzi, A.; Voigtlander, T.; Ferrier, P.; Ferrari, S.; Bianchi, M.E. The lack of chromosomal protein Hmg1 does not disrupt cell growth but causes lethal hypoglycaemia in newborn mice. Nat. Genet. 1999, 22, 276-280. [CrossRef]

40. Yao, L.; Lv, X.; Wang, X. MicroRNA 26a inhibits HMGB1 expression and attenuates cardiac ischemia-reperfusion injury. J. Pharmacol. Sci. 2016, 131, 6-12. [CrossRef]

41. Wang, Y.; Ouyang, M.; Wang, Q.; Jian, Z. MicroRNA-142-3p inhibits hypoxia/reoxygenationinduced apoptosis and fibrosis of cardiomyocytes by targeting high mobility group box 1. Int. J. Mol. Med. 2016, 38, 1377-1386. [CrossRef]

42. ESICM LIVES 2018: Paris, France. 20-24 October 2018. Intensive Care Med. Exp. 2018, 6, 40. [CrossRef]

43. Hawchar, F.; Laszlo, I.; Oveges, N.; Trasy, D.; Ondrik, Z.; Molnar, Z. Extracorporeal cytokine adsorption in septic shock: A proof of concept randomized, controlled pilot study. J. Crit. Care 2019, 49, 172-178. [CrossRef]

44. Gruda, M.C.; Ruggeberg, K.-G.; O’Sullivan, P.; Guliashvili, T.; Scheirer, A.R.; Golobish, T.D.; Capponi, V.J.; Chan, P.P. Broad adsorption of sepsis-related PAMP and DAMP molecules, mycotoxins, and cytokines from whole blood using CytoSorb(R) sorbent porous polymer beads. PLoS ONE 2018, 13, e0191676. [CrossRef]

45. Ekaney, M.L.; Otto, G.P.; Sossdorf, M.; Sponholz, C.; Boehringer, M.; Loesche, W.; Rittirsch, D.; Wilharm, A.; Kurzai, O.; Bauer, M.; et al. Impact of plasma histones in human sepsis and their contribution to cellular injury and inflammation. Crit. Care 2014, 18, 543. [CrossRef]

46. Silk, E.; Zhao, H.; Weng, H.; Ma, D. The role of extracellular histone in organ injury. Cell Death Dis. 2017, 8, e2812. [CrossRef]

47. Zima, A.V.; Blatter, L.A. Redox regulation of cardiac calcium channels and transporters. Cardiovasc. Res. 2006, 71, 310-321. [CrossRef]

48. Xu, K.Y.; Zweier, J.L.; Becker, L.C. Hydroxyl radical inhibits sarcoplasmic reticulum Ca(2+)-ATPase function by direct attack on the ATP binding site. Circ. Res. 1997, 80, 76-81. [CrossRef]

49. Xu, J.; Zhang, X.; Pelayo, R.; Monestier, M.; Ammollo, C.T.; Semeraro, F.; Taylor, F.B.; Esmon, N.L.; Lupu, F.; Esmon, C.T. Extracellular histones are major mediators of death in sepsis. Nat. Med. 2009, 15, 1318-1321. [CrossRef]

50. Kleine, T.J.; Lewis, P.N.; Lewis, S.A. Histone-induced damage of a mammalian epithelium: The role of protein and membrane structure. Am. J. Physiol. 1997, 273, 1925-1936. [CrossRef] 
51. Kleine, T.J.; Gladfelter, A.; Lewis, P.N.; Lewis, S.A. Histone-induced damage of a mammalian epithelium: The conductive effect. Am. J. Physiol. 1995, 268, 1114-1125. [CrossRef]

52. Alhamdi, Y.; Abrams, S.T.; Cheng, Z.; Jing, S.; Su, D.; Liu, Z.; Lane, S.; Welters, I.; Wang, G.; Toh, C.-H. Circulating Histones Are Major Mediators of Cardiac Injury in Patients with Sepsis. Crit. Care Med. 2015, 43, 2094-2103. [CrossRef]

53. Bosmann, M.; Ward, P.A. Protein-based therapies for acute lung injury: Targeting neutrophil extracellular traps. Expert Opin. Ther. Targets 2014, 18, 703-714. [CrossRef]

54. Lackner, I.; Weber, B.; Baur, M.; Haffner-Luntzer, M.; Eiseler, T.; Fois, G.; Gebhard, F.; Relja, B.; Marzi, I.; Pfeifer, R.; et al. Midkine Is Elevated After Multiple Trauma and Acts Directly on Human Cardiomyocytes by Altering Their Functionality and Metabolism. Front. Immunol. 2019, 10, 1920. [CrossRef]

55. Lackner, I.; Weber, B.; Knecht, D.; Horst, K.; Relja, B.; Gebhard, F.; Pape, H.-C.; Huber-Lang, M.; Hildebrand, F.; Kalbitz, M. Cardiac Glucose and Fatty Acid Transport After Experimental Mono- and Polytrauma. Shock 2019. [CrossRef]

(C) 2020 by the authors. Licensee MDPI, Basel, Switzerland. This article is an open access article distributed under the terms and conditions of the Creative Commons Attribution (CC BY) license (http://creativecommons.org/licenses/by/4.0/). 